\title{
SOCIO-DEMOGRAPHIC CORRELATES OF BREAST-FEEDING IN URBAN SLUMS OF CHANDIGARH
}

\author{
DINESH KUMAR, NEERAJ AGARWAL, H. M. SWAMI
}

ABSTRACT

RESEARCH QUESTION: Whether socio-demographic factors are associated with initiation of breast-feeding in urban slums of Chandigarh. OBJECTIVES: (1) To study the prevailing breast-feeding practices adopted by mothers, (2) To study the sociodemographic factors associated with initiation of breast-feeding. STUDY DESIGN Cross-sectional. PARTICIPANTS: Mothers of infants willing to participate in the study in the selected area. SAMPLE SIZE: A total of 270 respondents. STUDY VARIABLES: Social and demographic characteristics like age, socioeconomic status, educational level, birth interval, parity, gender preference, natal care practices, etc.; and variables related to various aspects of breast-feeding practices like prelacteal feed, initiation of feeding, colostrum feeding, reasons of discarding colostrum, etc. STATISTICAL ANALYSIS: Chi-square test and odd ratios along with their respective 95\% confidence intervals, multiple logistic regression analysis. RESULTS: Out of all 270 respondents, 159 (58.9\%) initiated breast-feeding within 6 h of birth, only 43 (15.9\%) discarded colostrum and 108 (40.0\%) mothers gave prelacteal feed. Illiterate/ iust literate mothers who delivered at home were found at significantly higher risk of delay in initiation of breast-feeding on the basis of multiple logistic regression analysis. SUGGESTIONS: Promotion of institutional deliveries and imparting health education to mothers for protecting and promoting optimal breast-feeding practices are suggested.

Key words: Breast-feeding behavior, colostrum feeding, prelacteal feed

It is believed that breast-feeding is universally and traditionally practiced in India. National Family Health Survey (NFHS) ${ }^{[1]}$ reports that $96 \%$ of children in India are breast-fed. Medical and public health experts

Department of Community Medicine, Govt. Medical College and Hospital, Chandigarh, India advocate breast-feeding as the best method of feeding young infants for a wide variety of reasons. Breast-feeding improves growth and development of children and also has some significant effects on mothers. Majority of infant deaths can be averted by promoting proper breast-feeding practices. WHO and UNICEF recognize well the beneficial effects of breast-feeding on maternal and child health.

There is a great inconsistency in findings regarding prevalence and correlates of breastfeeding behavior of mothers in different parts of the country. ${ }^{[2-4]}$ Knowledge, ignorance, undesirable sociocultural beliefs and misconceptions prevailing in the community are reported to influence breast-feeding behavior of mothers. ${ }^{[5,6]}$

Detailed account of breast-feeding practices in peri-urban community of Chandigarh is available in a recent study, ${ }^{[7]}$ but this study lacks socio-demographic correlates of breastfeeding. Growing urbanization and rapidly changing lifestyle in Chandigarh may also affect the breast-feeding behavior of mothers. Therefore, the present study was undertaken to study the prevailing breast-feeding practices and to investigate sociodemographic factors associated with initiation of breast-feeding in urban slums of Chandigarh.

\section{MATERIALS AND METHODS}

A cross-sectional study was conducted during October to November 2004 in catchment area of rural health training centre (RHTC), Palsora, affiliated to the Department of Community Medicine, Government Medical College and Hospital, Chandigarh. Chandigarh is the most economically advanced Union Territory of India and also the capital of two states: Punjab and Haryana. According to 2001 Census, the population of Chandigarh was 900,914 , with a sex ratio of 773 females per 1,000 males. According to statistical abstract of Chandigarh (2003), urban slum population of Chandigarh has a literacy rate of $55.46 \%$ and a sex ratio of 707 females per 1,000 males. RHTC caters health services to a population of about 35,000 spread in 10 urban wards / slums of Chandigarh.

An optimum sample size of 268 respondents was calculated on the basis of a pilot survey result reporting about $45 \%$ mothers initiating breast-feeding late - after $6 \mathrm{~h}$ of birth, with $90 \%$ confidence coefficient and $5 \%$ permissible error. A random sample of fou slum areas covering a sampled population of about 12,000 was selected in order to get a sample of requisite size. All mothers of infants in selected slums were identified and 270 of these mothers who gave their consen to participate in the study were included as study subjects. A pre-tested semi-structured schedule was used to collect the information from mothers regarding background and social and demographic characteristics like age, socioeconomic status, educational level, birth interval, natal care practices, parity, gender preference, etc. Mothers were also interviewed for various aspects of breast feeding practices like prelacteal feed, initiation of feeding, colostrum feeding and reasons of delay in initiation of breast-feeding and discarding colostrum, etc.

Modified Prasad classification ${ }^{[8]}$ adjusted fo current income levels was used fo socioeconomic classification. Chi-square tes and odds ratios along with their 95\% confidence intervals were used for finding factors associated with breast-feeding behavior on the basis of bivariate analysis. Multiple logistic regression analysis with stepwise forward selection of variables was used to find risk factors of delayed initiation of breast-feeding. 


\section{RESULTS}

A total of 270 mothers of infants were interviewed. The overall mean age of respondents was found to be $25.4 \pm 4.01$ years. Majority of respondents (55.5\%) belonged to age group 19-25 years; they were mostly Hindus ( $81.1 \%$ ) belonging to low socioeconomic status $(74.8 \%)$. Out of the total respondents, 132 (48.9\%) were either illiterates or just literate who could read and write but had no formal education. In 142 (52.6\%) cases, deliveries were conducted at home but only $26(9.6 \%)$ by untrained birth attendants [Table 1].

The mean parity of mothers was $2.10 \pm 1.08$ and the mean interval between two successive births was observed to be $39.18 \pm 2.12$

Table 1: Respondents by background characteristics

\begin{tabular}{lcc}
\hline Characteristics & No. & $\%$ \\
\hline Age in years & & \\
$<18$ & 07 & $(2.6)$ \\
$19-25$ & 150 & $(55.5)$ \\
$26-35$ & 98 & $(36.3)$ \\
$36-45$ & 15 & $(5.6)$ \\
Mean \pm SD & & $25.40 \pm 4.01$ \\
Educational status & 132 & $(48.9)$ \\
Illiterate/just literate & 28 & $(10.4)$ \\
Primary (class I to V) & 48 & $(17.8)$ \\
Middle (class V to VIII) & 48 & $(14.1)$ \\
High school (class IX to X) & 38 & $(8.9)$ \\
Others higher classes & 24 & $(81.1)$ \\
Religion & 219 & $(5.9)$ \\
Hindu & 16 & $(10.7)$ \\
Muslim & 29 & $(2.2)$ \\
Sikh & 6 & $(74.8)$ \\
Other & 202 & $(19.6)$ \\
Socio-economic status & 53 & $(5.6)$ \\
Low & 15 & \\
Middle & & \\
High & 142 & $(52.6)$ \\
Place of delivery & 128 & $(47.4)$ \\
Home & \\
Institution & 132 & $(48.9)$ \\
Birth attendant & $(42.5)$ \\
Trained dai & 26 & $(9.6)$ \\
Doctor & & $(100.00)$ \\
Untrained personnel & 270 & \\
Total & & \\
\hline
\end{tabular}

months. Out of 175 mothers having at least two children, $73(41.7 \%)$ had birth spacing of more than 36 months. Only 66 (24.4\%) mothers were having a 'son' preference for their last delivery. The mean age of infants was found to be $6.34 \pm 3.69$ months [Table 2].

Most of the mothers studied (142 [52.6\%]) initiated breast-feeding within 1-6 $\mathrm{h}$ of birth and only $17(6.3 \%)$ could initiate breast-feeding within $1 \mathrm{~h}$ of birth. There were 88 (32.6\%) mothers who reported initiating breast-feeding after $24 \mathrm{~h}$ of birth. The average time of initiating breast-feeding was found to be 16.44 h. Median time at initiation of breast-feeding was found to be $5.7 \mathrm{~h}$. Family restrictions $(38.8 \%)$, followed by social customs and religious beliefs prevalent in the community $(25.2 \%)$, were mainly found to be responsible for the delay in initiating breast-feeding [Table 3].

Only $43(15.9 \%)$ mothers discarded colostrum. Family restrictions (30.2\%),

Table 2: Respondents by reproductive characteristics

\begin{tabular}{lcc}
\hline Characteristics & No. & $\%$ \\
\hline Parity & & \\
1 & 95 & $(35.2)$ \\
2 & 88 & $(32.6)$ \\
3 & 63 & $(23.3)$ \\
$4-6$ & 24 & $(8.9)$ \\
Mean \pm SD & & \\
Birth spacing* in months $(\mathrm{n}=175)$ & & \\
$\quad 12-24$ & 53 & $(30.3)$ \\
$25-36$ & 49 & $(28.0)$ \\
$36+$ & 73 & $(41.7)$ \\
Mean \pm SD & & \\
Gender (son) preference & & \\
$\quad$ Yes & 66 & $(24.4)$ \\
$\quad$ No & 204 & $(75.6)$ \\
Age of Infant (months) & & \\
$\quad$ Below one & 31 & $(11.5)$ \\
$2-4$ & 71 & $(26.3)$ \\
$5-6$ & 39 & $(14.4)$ \\
$7-9$ & 61 & $(22.6)$ \\
$10-12$ & 68 & $(25.2)$ \\
Mean \pm SD & $6.34 \pm 3.69$ & \\
Overall & 270 & $(100.00)$ \\
Ber
\end{tabular}

${ }^{*}$ Between two successive births
Table 3: Breast-feeding initiation practices of mothers

\begin{tabular}{lcc}
\hline Practice & No. & $\%$ \\
\hline Initiation of BF (hrs.) $(\mathrm{n}=270)$ & & \\
$\quad$ Within one hour & 17 & $(6.3)$ \\
$\quad 1-6$ & 142 & $(52.6)$ \\
$7-24$ & 23 & $(8.5)$ \\
$25-72$ & 80 & $(29.6)$ \\
$72+$ & 8 & $(3.0)$ \\
Mean $\pm \mathrm{SD}$ & $16.44 \pm 6.34$ & \\
Reasons of delay in initiation of breast & & \\
feeding beyond 6 hours (N=111) & 43 & $(38.8)$ \\
Family restrictions & 28 & $(25.2)$ \\
Social customs and religious reasons & 12 & $(10.8)$ \\
Delayed lactation & 11 & $(9.9)$ \\
Mother's illness & 9 & $(8.1)$ \\
Inability/disinterest of baby to suck & 4 & $(3.6)$ \\
Cessarian section delivery & 5 & $(4.5)$ \\
Others & & \\
& &
\end{tabular}

followed by social customs (25.6\%), were the main reasons for discarding colostrum. Prelacteal feed was given in 108 (40.0\%) cases; cow's milk (64.8\%) and honey (13.9\%) came out to be the two most common prelacteal feeds [Table 4].

Risk factors of late initiation of breast-feeding were analyzed by calculating odds ratios based on bivariate analysis and adjusted odds ratios based on logistic regression model [Table 5]. On the basis of bivariate analysis, the following were found to be significantly associated $(P<0.05)$ with delay

Table 4: Practices related with colostrum feeding, prelacteal feed and frequency of feeding

\begin{tabular}{lcc}
\hline Practice & No. & $\%$ \\
\hline Colostrum given $(n=270)$ & 227 & $(84.1)$ \\
Reasons of not giving $(\mathrm{n}=43)$ & 13 & $(30.2)$ \\
Family restrictions & 11 & $(25.6)$ \\
Social customs & 9 & $(20.9)$ \\
Problem in secretions & 7 & $(16.3)$ \\
Misconceptions & 7 & $(16.3)$ \\
Others & & $(64)$ \\
Prelacteal feeds $(n=108)$ & 70 & $(64.8)$ \\
Cow's milk & 75 & $(13.9)$ \\
Honey & 7 & $(6.5)$ \\
Sweet water & 4 & $(3.7)$ \\
Ghutti & 4 & $(3.7)$ \\
Sister in law's milk & 3 & $(2.3)$ \\
Diluted milk (not cow) & 5 & $(4.6)$ \\
Others & &
\end{tabular}

in initiation of breast feeding: maternal age, literacy, socioeconomic status and place of delivery. Religion, birth attendant, parity, birth spacing, gender of baby and gender preference were not found to be its significant correlates. Delayed initiation of breast-feeding was found more common among illiterate mothers of low socioeconomic status. However, other factors like religion, birth attendant, parity, birth spacing, gender, etc, did not affect significantly $(P>0.10)$ the initiation of breast-feeding. On the basis of multivariate logistic regression analysis, some of these factors associated with initiation of breast-feeding lost their significance. Mothers delivering at home and who were illiterate were found at a significantly higher risk of delay in initiation of breastfeeding beyond $6 \mathrm{~h}$. Other factors lost their significance in logistic regression analysis.

\section{DISCUSSION}

The average time of initiating breast-feeding was found to be $16.44 \mathrm{~h}$, which was quite high. There was considerable delay in initiation of breast-feeding. Breast-feeding was delayed mostly due to family restrictions. In the present study, $67.4 \%$ mothers initiated breast-feeding within $24 \mathrm{~h}$. An increasing trend of mothers starting breast milk within $24 \mathrm{~h}$ was reported in Chandigarh $(25 \%$ in $1974 ; 41 \%$ in 1984$)^{[9]}$ and $41.4 \%$ was reported in the peri-urban community of Chandigarh. ${ }^{[7}$ In some other studies, ${ }^{[4,10]}$ comparatively smaller proportions of mothers initiating breast-feeding within $24 \mathrm{~h}$ has been reported. Very low percentages of mothers initiating breast-feeding within $1 \mathrm{~h}(13 \%)$ and within 1 day of birth $(29 \%)$ have been reported in 
Table 5: Bivariate and multivariate analysis of risk factors of delayed initiation of breast-feeding

\begin{tabular}{lcccccccc}
\hline Risk Factor & \multicolumn{3}{c}{ Bivariate analysis } & & \multicolumn{3}{c}{ Multivariate logistic regression analysis } \\
\cline { 2 - 4 } \cline { 7 - 9 } & Odds ratio & $95 \%$ Cl of OR & $P$-value & & Adjusted odds ratio & $95 \%$ Cl of AOR & $P$-value \\
\hline Religion other than Hindu & 0.82 & $(0.42-1.60)$ & 0.53 & & 0.99 & $(0.51-1.94)$ & 0.99 \\
Low SES & $1.80^{\star}$ & $(0.97-3.37)$ & 0.04 & & 1.28 & $(0.58-2.13)$ & 0.45 \\
Untrained birth attendant & 1.49 & $(0.62-3.59)$ & 0.33 & & 1.06 & $(0.43-2.43)$ & 0.88 \\
Home delivery & $2.15^{\star}$ & $(1.27-3.64)$ & 0.002 & & $2.25^{*}$ & $(1.02-2.51)$ & 0.005 \\
Birth order above two & 1.54 & $(0.89-2.67)$ & 0.09 & & 0.82 & $(0.58-2.13)$ & 0.51 \\
Birth spacing >24 months & 1.94 & $(0.86-4.42)$ & 0.08 & & 1.10 & $(0.58-2.13)$ & 0.71 \\
No gender preference & 0.86 & $(0.47-1.56)$ & 0.59 & & 0.60 & $(0.58-2.13)$ & 0.10 \\
Age $>25$ & $2.27^{\star}$ & $(1.33-3.88)$ & $<0.01$ & & 1.33 & $(0.58-2.13)$ & 0.45 \\
Literacy & $0.58^{*}$ & $(0.58-0.98)$ & 0.03 & & $0.64^{\star}$ & $(0.58-1.13)$ & 0.04 \\
\hline
\end{tabular}

${ }^{*}$ Represents significant value of odds ratios, OR - Odds ratio, AOR - Adjusted odds ratio

NFHS-2 data ${ }^{[1]}$ also.

common prelacteal feed administered.

Only about $16 \%$ of surveyed mothers discarded colostrum compared to $34 \%$ found earlier in peri-urban area of Chandigarh, ${ }^{[7]} 5 \%$ in Haryana ${ }^{[3]}$ and about $33 \%$ in another study. ${ }^{[11]}$ Some other studies report high percentages of mothers discarding colostrum $^{[12-14]}$ in different populations. Data complied by NFHS-2 also give a high incidence of discarding colostrum in both rural and urban areas. ${ }^{[1]}$ Reasons given by mothers for discarding colostrum in the present study were mainly family restrictions and social customs.

The prevalence of giving prelacteal feeds was found to be $40 \%$, in contrast to $97.7 \%$ found earlier in the peri-urban community of Chandigarh. ${ }^{[7]}$ Some other studies ${ }^{[4,14]}$ also reported high prevalence of giving prelacteal feeds in different populations. The low prevalence of giving prelacteal feed observed in the present study may be due to high prevalence of colostrum feeding and a comparatively early initiation of feeding. Prelacteal feeds are usually administered due to colostrum deprivation and delayed initiation of breast-feeding, apart from some social customs and beliefs. Cow's milk was the most initiated late by mothers in slum areas of Chandigarh, mainly due to family restrictions and interference of elderly females. Delayed initiation of breast-feeding was more common among illiterate mothers delivering at home, irrespective of their other socio-demographic characteristics like religion, parity, birth spacing, gender of baby, gender preference, etc. The study suggests a need for dissemination of information and education regarding optimal breast-feeding practices and for protecting and promoting healthy traditional practices. Involvement of pregnant and lactating mothers, elderly women and also adolescent girls in various IEC activities is desirable as they all have an important role in initiation of breast-feeding and other healthy feeding practices at the community level. They should be made aware of advantages and psychological implications of optimal breast-feeding practices. Efforts should also be made for promoting institutional deliveries for providing them better opportunities of health education for early initiation of breast-feeding.

\section{ACKNOWLEDGMENT}

Authors are highly grateful to the referees for their valuable comments for improving this paper. The assistance provided by Mr. Parminder Kumar, data entry operator in the Department of Community Medicine, Govt. Medical College, Chandigarh, in typing of the manuscript is also acknowledged.

\section{REFERENCES}

1. National Family and Health survey 1998-99, International Institute for Population Sciences, Mumbai, India ORC Macro: Maryland, USA October 2000.

2. Bhardwaj N, Hasan SB, Yunus M, Zaheer M. High risk pregnancy and its relation with maternal care receptivity (MCR) - A rural study from India. J R
Soc Health 1991:111:43-6.

3. Singh S, Bhasin SK, Ingle GK, Raut DK. Pattern of breast-feeding practices in a rural community from Haryana. J Trop Pediatr 1990;36:334-5.

4. Srivastava SP, Sharma VK, Kumar V. Breast feeding pattern in neonates. Indian Pediatr 1994;31:1079-82.

5. Jeeson UC, Richard J. Factors influencing breastfeeding behavior. Indian Pediatr 1989;26:9971002.

6. Kumar S, Nath LM, Reddaiah VP. Factors influencing prevalence of breastfeeding in a resettlement colony of New Delhi. Indian J Pediatr 1989;56:385-91.

7. Swami HM, Bhatia V, Bhatia SP. Breast-feeding practices in peri-urban community of Chandigarh. Indian J Prev Soc Med 2002;33.

8. Kumar P. Social classification - Need for constan updating. Indian J Commun Med 1993;18:60-1.

9. Walia BN, Gambhir SK, Sroa SR, Chaudhary S. Decline in breast-feeding practices in urban population of Chandigarh, during a decade. Indian Pediatr 1987;24:879-87.

10. Gupta AK, Sood RK, Vatsayan A, Dhadwal DK, Ahluwalia SK, Sharma RK. Breast feeding practices in rural and urban communities in a hilly district of North India. Indian J Commun Med 1997;23:33-7.

11. Reddy S. Breastfeeding - Practices, problems and prospects. J Fam Welfare 1995;41:43-51.

12. Banapurmath $C R$, Nagaraj MC, Banapurmath $S$, Kesaree N. Breast feeding practice in villages of Central Karnataka. Indian Pediatr 1996;33:477-9.

13. Bavdekar SB, Bardekar MS, Kasla RR Raghunandana KJ, Joshi SY, Hathi GS. Infant feeding practices in Bombay slums. Indian Pediatr 1994;31:1083-7.

14. Sethi V, Kashyap S, Seth V. Effect of nutrition education of mothers on infant feeding practices. Indian J Pediatr 2003;70:463-6.

15. Kar M, Dey R. Breast feeding practices Impressions from an urban community. Indian $J$ Pub Health 1991;35:93-6.

The concludes that breast-feeding was 